\title{
Structural and Functional Properties of Venous Wall: Relationship between Elastin, Collagen, and Smooth Muscle Components and Viscoelastic Properties
}

\author{
Yanina Zócalo, ${ }^{1}$ Daniel Bia, ${ }^{1}$ Edmundo I. Cabrera-Fischer, ${ }^{2,3}$ Sandra Wray, ${ }^{2}$ \\ Cintia Galli, ${ }^{2,4}$ and Ricardo L. Armentano ${ }^{1,2,4}$ \\ ${ }^{1}$ Physiology Department, School of Medicine, CUiiDARTE, Republic University, General Flores 2125, 11800 Montevideo, Uruguay \\ ${ }^{2}$ Favaloro University, C1093AAS Buenos Aires, Argentina \\ ${ }^{3}$ National Council of Technical and Scientific Research (CONICET), C1033AAJ Buenos Aires, Argentina \\ ${ }^{4}$ Technological National University, C1179AAQ Buenos Aires, Argentina
}

Correspondence should be addressed to Daniel Bia; dbia@fmed.edu.uy

Received 11 March 2013; Accepted 7 April 2013

Academic Editors: Y. Ootsuka and W. Shen

Copyright (C) 2013 Yanina Zócalo et al. This is an open access article distributed under the Creative Commons Attribution License, which permits unrestricted use, distribution, and reproduction in any medium, provided the original work is properly cited.

\begin{abstract}
The aims of this work were (1) to analyze the viscoelastic behavior of different venous segments and their differences, considering the structural characteristics (elastin, collagen, and smooth muscle content) of the venous wall; (2) to analyze the venous biomechanical behavior by means of the histological characteristics of the veins. Nine healthy male Corriedale sheep were included. One vein was selected from each animal to evaluate its biomechanical properties: (a) anterior vena cava, (b) right jugular vein, and (c) right femoral vein. Each selected vein was instrumented with pressure and diameter sensors. After excision, a small ring-shaped sample was set apart from each segment for histological analysis. The amounts of elastin, collagen and smooth muscle were correlated to calculated biomechanical parameters (high- and low-pressure compliance and viscosity). Conclusions are the following: (1) the viscoelastic behavior of the venous wall varies depending on the vascular territory, and it is associated with the variation of the histological structure. These differences involve muscle (both smooth and striated), elastin, and collagen contents. (2) In addition, the quantity of collagen was negatively correlated with high- and low-pressure compliances, and (3) the smooth muscle content was higher in peripheral veins and is positively correlated with venous wall viscosity.
\end{abstract}

\section{Introduction}

The use of veins as grafts has been introduced in clinical practice with several purposes: (a) aortocoronary saphenous vein grafts in myocardial direct revascularization [1]; (b) to perform arteriovenous fistulae in hemodialyzed patients [2]; (c) to perform peripheral revascularization, including the confection of interposing vein cuffs in expanded polytetrafluoroethylene bypasses [3]. For the aforementioned reasons, the use of veins has been extensively indicated in both ischemic and hemodialyzed patients. However, there are several complications, such as intimal hyperplasia, which has been considered to be produced by a mechanical mismatch between the native arteries and the grafts [4]. Consequently, the functional parietal biomechanical behavior of blood vessels has an essential role determining the performance of the cardiovascular system, both in physiological and pathological conditions. Even though this is true for both veins and arteries, there is an imbalance between the existing studies and available information regarding the arterial wall and those related to the venous wall mechanics, which could be explained through several factors (e.g., methodological limitations, functional meaning of parietal mechanics, etc.). On the other hand, the biomechanical studies conducted on the venous wall correspond mainly to the field of strength of materials and are nonrealistic, static, and carried out in nonphysiological conditions [5]. Furthermore, most works do not refer to the viscous response of the wall [6]. In this context, the purpose of this work includes the characterization of the venous functional biomechanical behavior, through 
the analysis of the dynamic biomechanical response of the venous wall, under a hemodynamic setting that resembles physiological conditions.

The workload and functional requirements, as in arteries, are not homogeneous in the venous system; instead, they vary between veins of different calibers or territories. Consequently, the biomechanical response and the parietal functional capacity may differ, depending on the observed vein. Furthermore, the wall behavior and its differences may be related to the anatomohistological characteristics of the venous wall. Regarding the latter, the biomechanical response of different veins was characterized and compared, and the results were analyzed considering the wall structure (i.e., distribution and amounts of collagen, elastin, and smooth muscle).

In this context, the aims of this work were: (1) to analyze the viscoelastic behavior of several venous segments and their differences, considering the structural contents (i.e., elastin, collagen, and smooth muscle content) of the venous wall; (2) to analyze the venous biomechanical behavior by means of the histological characteristics of the veins. To this end, this study involved the histological analyses in ovine venous segments, with the purpose of characterizing their absolute and relative amount of elastin, collagen, and muscle (smooth and striated), and the characterization of the biomechanical behavior in a mock circulation-loop, in pulsatile hemodynamic settings resembling physiological conditions. The ovine model used in this work is considered useful to mimic the venous function, allowing the development of new graft designs and therapies [7].

\section{Methods}

The experimental protocol was approved by the Research and Development Council of the participant institutions and was conducted in accordance with the National Institutes of Health Guidelines for the care and use of laboratory animals (U.S.N.R. Council, Guide for the Care and Use of Laboratory Animals, Washington, DC: National Academy Press, 1996).

Nine healthy male Corriedale sheep were included in this study, weighing 25-35 kg and aged between 12 and 16 months. All animals were vaccinated and treated for internal and external parasites by a specialized veterinary team. Their clinical status was controlled during the 20 days prior to the experimental surgeries. All animals were anaesthetized using $35 \mathrm{mg} \cdot \mathrm{kg}^{-1}$ of intravenous sodium pentobarbital. Mechanical respiratory assistance was performed in all cases (SIMV Pulmolog, Polymed 201, Draeger, Hispania, S.A., Spain). In order to monitor respiratory parameters, a pulse oximeter was used (Pulse Oximeter 515A, Novametrix Medical Systems Inc., Wallingford, USA). Respiratory rate and tidal volume were checked and maintained between physiological ranges: arterial $\mathrm{pCO}_{2}$ at $35-45 \mathrm{mmHg}, \mathrm{pH}$ at 7.35-7.45, and $\mathrm{pO}_{2}$ above $80 \mathrm{~mm} \mathrm{Hg}$. An electric blanket was used to maintain the corporal temperature at $37.5^{\circ} \mathrm{C}$.

In each animal, one vein segment was selected from (a) anterior vena cava, (b) right jugular vein, or (c) right femoral vein, in order to evaluate its biomechanical properties. Two suture stitches were used to delimitate in vivo a $6 \mathrm{~cm}$ length venous segment, accurately measured with a caliper, according to the technique previously reported [3]. Two miniature piezoelectric crystal transducers (5 MHz, $2 \mathrm{~mm}$ in diameter) were positioned on opposite sides of each selected vessel and sutured to the adventitia in order to measure the external diameter of the vein. The correct position of the ultrasonic crystals was ensured using an oscilloscope (model 465B, Tektronix, Beaverton, OR, USA). Transit time was converted to distance using a sonomicrometer $(1000 \mathrm{~Hz}$ frequency response, Triton Technology Inc., San Diego, CA, USA). The diameter measurement instruments were calibrated using the internal calibration system of the sonomicrometer. After in vivo confirmation of the adequate quality of the diameter signal, each animal was euthanatized with an intravenous overdose of sodium thiopental, followed by potassium chloride. Each venous segment was analyzed in vitro after being nontraumatically mounted at its in vivo length in a circulating loop that mimics the in vivo state, allowing a dynamic mechanical study [3]. The in vitro setup consisted of a pneumatic pump (Jarvik Model 5, Kolff Medical Inc.), a polyethylene perfusion line with variable flow resistances and a Windkessel chamber. During the in vitro experiments, each vascular segment was kept immersed and perfused with thermally regulated $\left(37^{\circ} \mathrm{C}\right)$ and oxygenated Tyrode's solution $(\mathrm{pH}=7.4)$.

A small ring-shaped sample was set apart from each segment for posterior histological analysis. After checking that the diameter signal was correctly measured, a solid-state pressure microtransducer (Model P2.5, $1200 \mathrm{~Hz}$ frequency response; Konigsberg Instruments, Inc., Pasadena, CA, USA) was inserted in each venous segment. The pressure signal was visualized on the screen of a PC.

The in vitro setup was adjusted in order to obtain pressure values in a range of 0 to $60 \mathrm{mmHg}$ (Figure 1), at a stretching rate of $1.8 \mathrm{~Hz}=108$ beats. $\mathrm{min}^{-1}$. Both pressure and diameter signals were monitored and left to attain dynamic equilibrium during 10 minutes under steady-flow (approximately $\left.450 \mathrm{~mL} \cdot \mathrm{min}^{-1}\right)$. Pressure and diameter signals were digitalized using an $\mathrm{AD}$ converter, acquired using a Data Acquisition Board (PCI 1200, National Instruments, Austin, TX, USA) and stored in a PC (Pentium 4, 2.6 GHz). In all experiments, we used a program developed in our laboratory in LabView 5.1.1 language (National Instruments, Austin, TX, USA) that allowed obtaining 20 to 30 beats in steady-state conditions, which were sampled at a frequency of $200 \mathrm{~Hz}$.

2.1. Data Analysis. The instantaneous pressure and diameter signals were plotted against each other to obtain the pressure-diameter loop for each segment (Figure 1(b)), which showed enclosed hysteresis areas that represent the viscous component of the venous wall. In order to characterize the biomechanical behavior and to calculate the viscoelastic parameters, the venous wall is represented using the KelvinVoigt, according to which the total pressure in the wall can be divided into an elastic and a viscous component [8] as follows:

$$
P_{\text {total }}=P_{\text {elastic }}+P_{\text {viscous }} \text {. }
$$




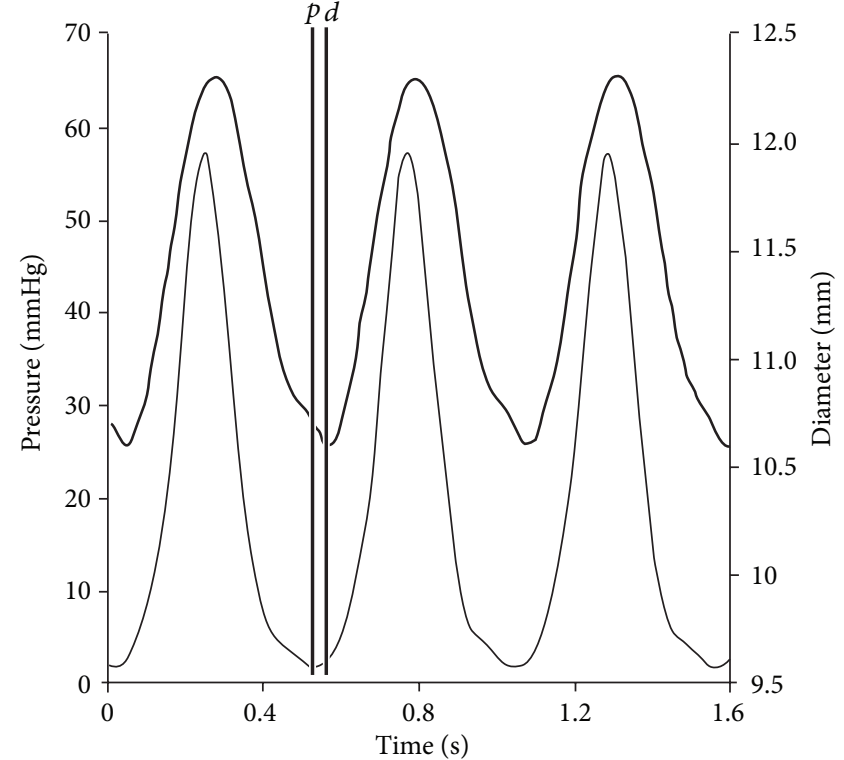

(a)

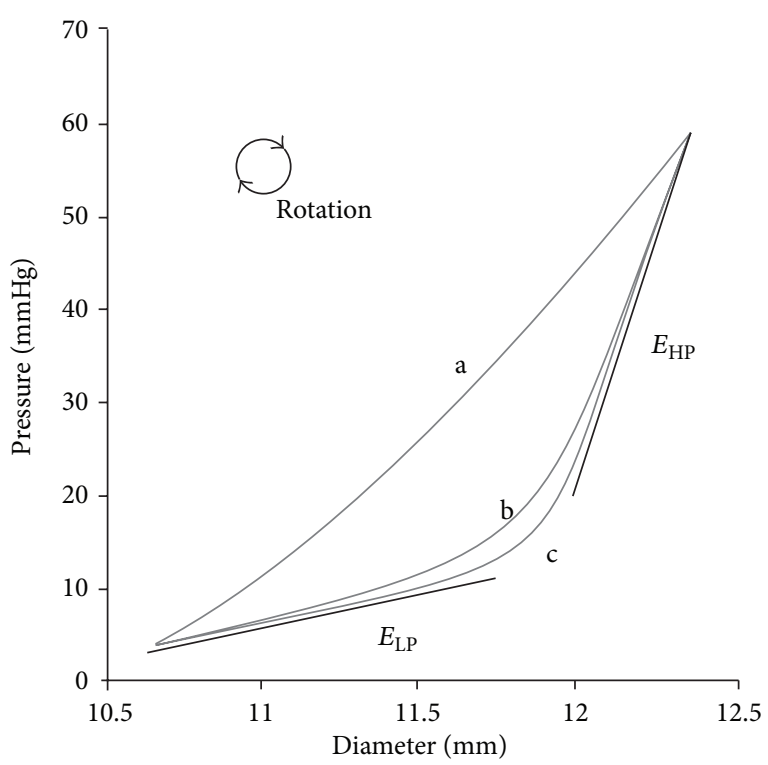

(b)

FIGURE 1: (a): Instantaneous pressure and diameter signals obtained during in vitro experiments on the cava vein. Note the phase lag between the pressure and diameter signals; $p$ and $d$ show the foot-to-foot difference. (b) Pressure-diameter relationship (clockwise rotation) obtained from the signals plotted in (a), showing a hysteresis area that represents the vascular viscosity. The a-c loop is the original pressure-diameter relationship, and the b-c loop is the purely elastic pressure-diameter relationship. $E_{\mathrm{LP}}$ : elastic modulus for low pressure-diameter relationship; $E_{\mathrm{HP}}$ : elastic modulus for high pressure-diameter relationship.

The viscous component is proportional to the first derivative of the diameter with respect to time $(d D / d t)$, and so (1) can be rewritten as

$$
P_{\text {elastic }}=P_{\text {total }}-\eta \cdot \frac{d D}{d t},
$$

where $\eta$ is the viscous modulus ( $\mathrm{mm} \mathrm{Hg} \cdot \mathrm{s} \cdot \mathrm{mm}^{-1}$ ). In order to characterize the venous wall viscosity, the viscous term is subtracted from the total pressure, seeking the minimization of the hysteresis area [8]. This method, described by Bauer et al. consists in progressively augmenting the viscous modulus (see (2)) until the hysteresis loop is minimized, while maintaining a clockwise rotation [9-11]. The value that best fits those requirements is considered the viscous modulus [8]. Once the hysteresis area is minimized, the elastic modulus $E$ can be calculated for both high $\left(E_{\mathrm{HP}}\right)$ and low pressure levels $\left(E_{\mathrm{LP}}\right)$, above and below the breakpoint, respectively (Figure 1(b)). The obtained elastic moduli were expressed as Compliance $(C, C=1 / E)$.

2.2. Histological Studies. The nine small ring-shaped samples set apart from each segment were submitted to histological analysis. These venous segments were fixed by immersion in buffered $10 \%$ formaldehyde and embedded in paraffin to obtain $7 \mu \mathrm{m}$ thick rings. All samples were then deparaffinized and hydrated and stained following the Cajal-Gallego staining method. In this way, a differential staining was obtained: the muscular cells in yellow-green, the elastin component in deep red, and the collagen fibers in light blue.
Then, the images of each sample were digitized on $630 \times 1024$ pixel frames, using an optical microscope $(400 \mathrm{X})$. In order to quantify the relative amount of each venous wall component, the obtained images were analyzed following the procedure used by our group [12], which was previously reported by Kawasaki et al. [13] (Figures 2, 3, and 4). The mentioned technique consists in removing the pixels that do not belong to the vascular tissues and counting the total amount of pixels contained in the whole image. Next, the amount of pixels for each individual component (i.e., elastin, collagen, and muscle) was determined. The relative amounts of the mentioned individual components were calculated as the percent proportion of the amount of pixels representing each coloring and the total amount of pixels (Figures 2, 3, and 4). The absolute amounts of each component can be determined from the afore mentioned calculated proportions. The sectional area is calculated as the difference between the total vascular area $\left(\pi \cdot\right.$ external radius $\left.{ }^{2}\right)$ and the luminal area $\left(\pi \cdot\right.$ internal radius $\left.{ }^{2}\right)$ [9]. The absolute quantity of each component $\left(\mathrm{mm}^{2}\right)$ is calculated as the relative amount (\%) times the total sectional area.

2.3. Statistical Analysis. All data is expressed as mean \pm standard deviation $(\mathrm{MV} \pm \mathrm{SD})$. The parameters obtained at high and low pressures were compared using a $t$-test. The multiple hemodynamic and biomechanical parameters were compared using ANOVA, followed by Bonferroni test. In order to find an association between biomechanical and histological data, regression analysis was performed. A $P<0.05$ value was adopted as statistically significant. SPSS software 


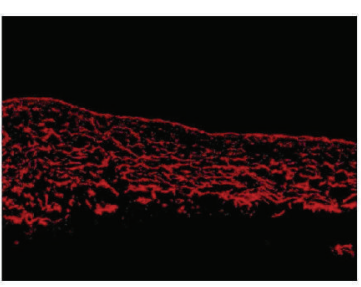

Elastin

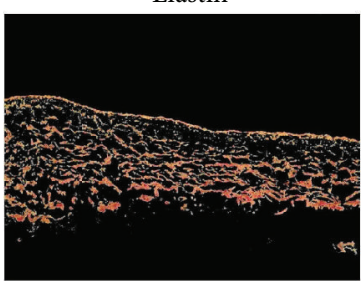

Femoral vein

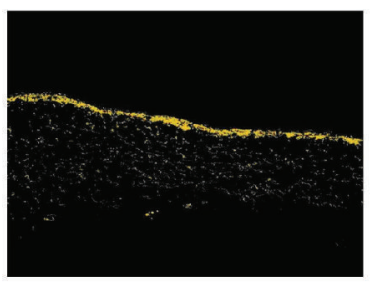

Muscle

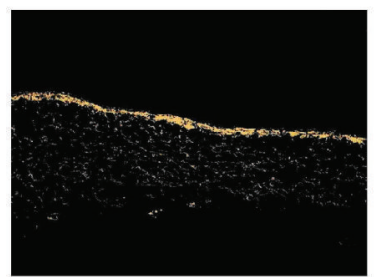

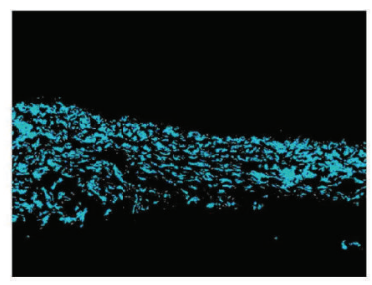

Collagen

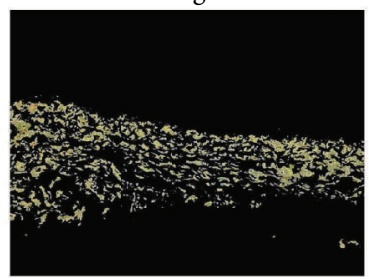

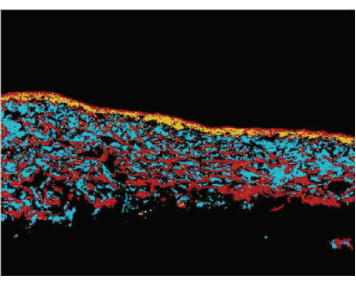

Total

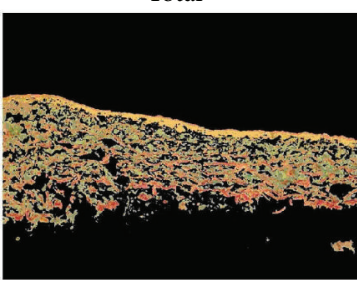

FIGURE 2: Illustration of the histological analysis processing stages in an ovine femoral vein. Bottom panel: characteristic colors of the histological preparations, from left to right: elastin, smooth muscle, collagen, and the original image, where the three integrated constituents can be visualized throughout the vascular wall. Top panel: similar discrimination with assigned fictional colors that allow a clearer visualization of the location of each wall constituent. Note the thin layer of smooth muscle and the large amount of elastic tissue.

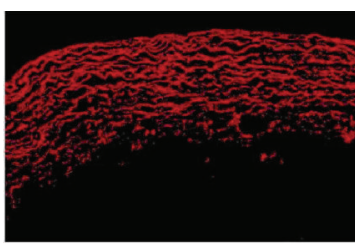

Elastin

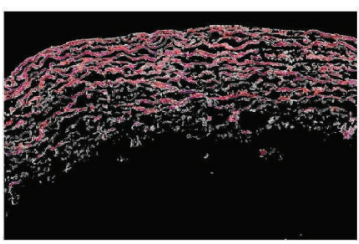

Jugular vein

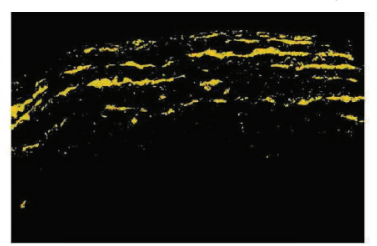

Muscle

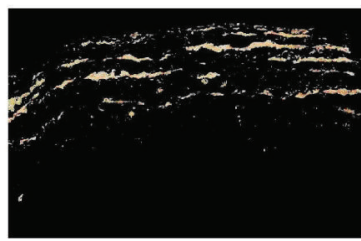

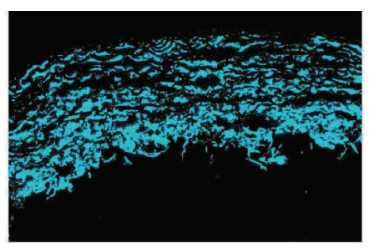

Collagen

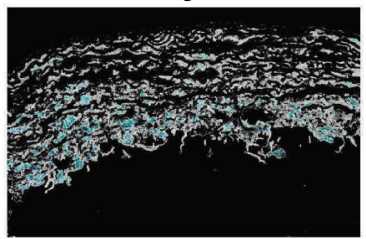

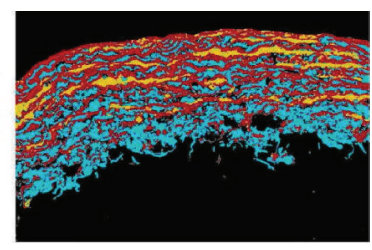

Total

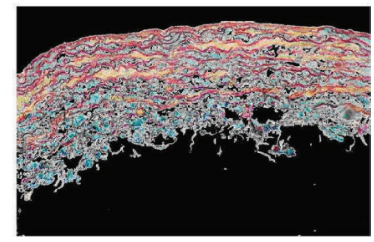

FIGURE 3: Illustration of the histological analysis processing stages in an ovine jugular vein. Bottom panel: characteristic colors of the histological preparations, from left to right: elastin, smooth muscle, collagen, and the original image, where the three integrated constituents can be visualized throughout the vascular wall. In the top panel, several thin muscular layers are visualized in the media.

(version 18.0, Statistical Package for the Social Sciences) was used to undertake all statistical analyses.

\section{Results}

In Table 1, the hemodynamic parameters obtained during in vitro studies of the nine analyzed vessels show the isobaric and isofrequency (equal pressure and stretch-rate) conditions to which all vein segments were submitted. As expected, the obtained diameter values showed significative differences among them $(P<0.05)$.

The elastic analyses demonstrated that high-pressure compliance values were consistently lower than those calculated for low-pressure compliance values $(P<0.05)$, in jugular, cava, and femoral veins. Both low- and high-pressure compliance values calculated for vena cava segments were higher than those corresponding to jugular and femoral vein segments $(P<0.05)$. On the other hand, the low and highpressure compliance values calculated for femoral vein segments were the lowest $(P<0.05)$ (Table 2$)$.

The histological analyses show structural differences among the three studied venous segments. In Figures 2, 3, and 4 , there are differences in the smooth muscle cell arrangement. In femoral veins, the thin muscular layer was located very close to the intima; in jugular veins, several thin layers were observed all through the media layer, while in the vena cava, several parallel thin layers were found close to the intima. They coexist with wide bundles of striated muscle placed in the media and external layers.

Table 3 shows that the relative value of smooth muscle measured in the vena cava was lower than that observed in the jugular vein $(P<0.05)$, while the comparison with the femoral vein shows a nonsignificative increase. This was also 

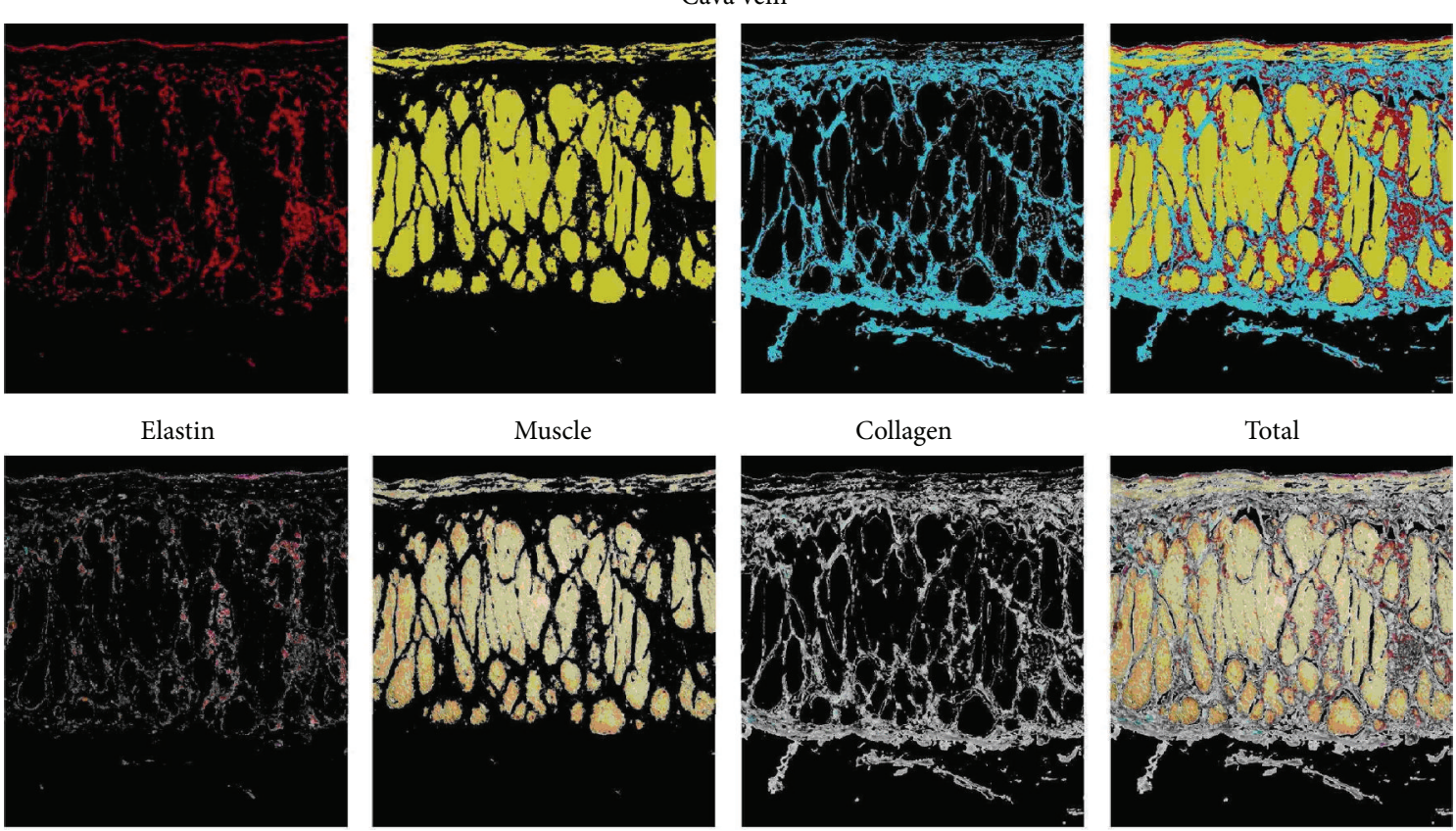

Total

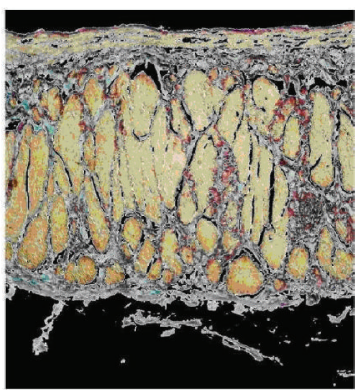

FIGURE 4: Illustration of the histological analysis processing stages in an ovine cava vein. Bottom panel: characteristic colors of the histological preparations, from left to right: elastin, smooth muscle, collagen, and the original image, where the three integrated constituents can be visualized throughout the vascular wall. Note that several parallel thin muscular layers are observed close to the intima, while wide bundles of striated muscle are visualized in the media and external layers.

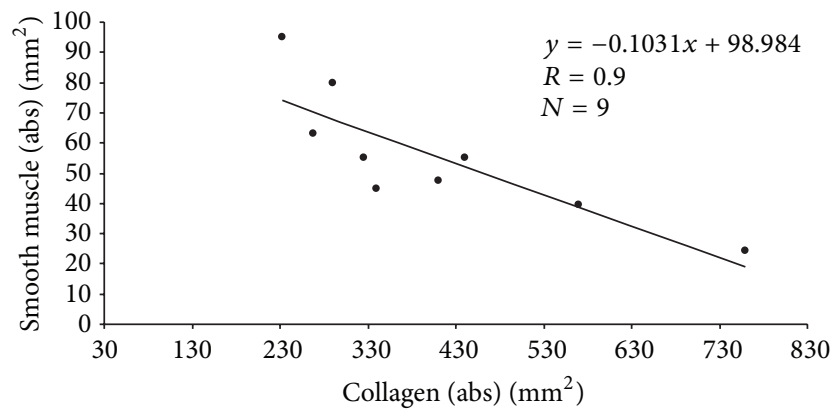

FIGURE 5: Negative association between the absolute amounts of smooth muscle and collagen in the venous wall. The linear relationship was statistically significant $(P<0.05)$.

the rule when the striated muscle was eliminated from the analysis. It is important to note that both the thickness and the parietal section of the vena cava showed the highest values $(P<0.05)$ compared with jugular and femoral veins.

With respect to the elastic tissue, the relative amounts of elastin and collagen measured in the vena cava were significantly lower than those observed in the jugular vein $(P<0.05)$. The femoral vein relative amounts of collagen and elastin were nonsignificatively higher than those observed in the vena cava. When the striated muscle was not considered as a part of the section area, the relative amount of elastin conserved the mentioned relationship, while collagen relative amounts measured in the vena cava were significantly higher than that observed in the jugular vein $(P<0.05)$.
TABLE 1: Hemodynamic parameters.

\begin{tabular}{lccc}
\hline & $\begin{array}{c}\text { Jugular vein } \\
\text { MV } \pm \mathrm{SD}\end{array}$ & $\begin{array}{c}\text { Vena cava } \\
\mathrm{MV} \pm \mathrm{SD}\end{array}$ & $\begin{array}{c}\text { Femoral vein } \\
\mathrm{MV} \pm \mathrm{SD}\end{array}$ \\
\hline$P_{\max }(\mathrm{mmHg})$ & $52 \pm 2$ & $53 \pm 5$ & $55 \pm 7$ \\
$P_{\min }(\mathrm{mmHg})$ & $2 \pm 1$ & $2 \pm 1$ & $2 \pm 1$ \\
$D_{\max }(\mathrm{mm})$ & $10.4 \pm 3.1$ & $13.5 \pm 1.6^{\mathrm{a}}$ & $6.1 \pm 0.6^{\mathrm{a}}$ \\
$D_{\min }(\mathrm{mm})$ & $9.2 \pm 3.1$ & $10.9 \pm 1.6^{\mathrm{a}}$ & $5.4 \pm 0.4^{\mathrm{a}, \mathrm{b}}$ \\
\hline
\end{tabular}

Mean value \pm standard deviation; $P$ : pressure; $D$ : diameter; Max: maximal; Min: minimal.

${ }^{\mathrm{a}} P<0.05$ with respect to jugular vein.

${ }^{\mathrm{b}} P<0.05$ with respect to vena cava.

The correlation study showed a negative association between the absolute amounts of smooth muscle and collagen tissue in the venous wall included in this analysis $(P<0.05)$ (Figure 5). The association between venous wall viscosity and the relative amounts of vascular smooth muscle was positive $(P<0.05)$. In Figure 6(a), a discriminative analysis was performed considering and not considering in the total area the striated muscle (only observed in the vena cava).

The collagen relative content of the vein wall was negatively associated with both low- and high-pressure compliance $(P<0.05)$ (Figure 7$)$.

\section{Discussion}

This work enabled the characterization and comparison of the venous viscoelasticity, analyzing the results while taking 
TABLE 2: Biomechanical parameters.

\begin{tabular}{lccc}
\hline & Jugular vein & Vena cava & Femoral vein \\
& MV \pm SD & MV \pm SD & MV \pm SD \\
\hline Low pressure compliance $\left(10^{-3} \mathrm{~m} \cdot \mathrm{kPa}^{-1}\right)$ & $2.03 \pm 0.23$ & $5.10 \pm 0.38^{\mathrm{a}}$ & $1.51 \pm 0.15^{\mathrm{a}, \mathrm{b}}$ \\
High pressure compliance $\left(10^{-3} \mathrm{~m} \cdot \mathrm{kPa}^{-1}\right)$ & $1.73 \pm 0.23^{*}$ & $4.88 \pm 0.45^{\mathrm{a} *}$ & $1.35 \pm 0.15^{\mathrm{a}, \mathrm{b} *}$ \\
Viscosity $\left(\mathrm{kPa} \cdot \mathrm{s} \cdot \mathrm{m}^{-1}\right)$ & $162.06 \pm 17.29$ & $53.20 \pm 7.87^{\mathrm{a}}$ & $203.49 \pm 30.59^{\mathrm{a}, \mathrm{b}}$ \\
\hline
\end{tabular}

Mean value $(\mathrm{MV}) \pm$ standard deviation $(\mathrm{SD})$.

${ }^{\text {a }} P<0.05$ with respect to jugular vein.

${ }^{\mathrm{b}} P<0.05$ with respect to vena cava.

${ }^{*} P<0.05$ with respect to the same vein in low pressure condition.

TABLE 3: Structural parameters obtained from histological analyses.

\begin{tabular}{|c|c|c|c|}
\hline & $\begin{array}{c}\text { Jugular vein } \\
\mathrm{MV} \pm \mathrm{SD}\end{array}$ & $\begin{array}{l}\text { Vena cava } \\
\mathrm{MV} \pm \mathrm{SD}\end{array}$ & $\begin{array}{c}\text { Femoral vein } \\
\mathrm{MV} \pm \mathrm{SD}\end{array}$ \\
\hline Smooth muscle (\%) & $11.08 \pm 4.18$ & $2.71 \pm 1.44^{\mathrm{a}}$ & $7.78 \pm 3.19$ \\
\hline Striated muscle (\%) & $0.00 \pm 0.00$ & $40.60 \pm 3.90^{\mathrm{a}}$ & $0.00 \pm 0.00^{\mathrm{b}}$ \\
\hline Total muscle (\%) & $11.08 \pm 4.18$ & $43.31 \pm 5.09^{\mathrm{a}}$ & $7.78 \pm 3.19$ \\
\hline Elastin (\%) & $47.13 \pm 3.08$ & $21.04 \pm 3.72^{\mathrm{a}}$ & $45.27 \pm 2.56$ \\
\hline Collagen (\%) & $41.78 \pm 2.84$ & $35.65 \pm 2.05^{\mathrm{a}}$ & $46.95 \pm 4.66$ \\
\hline Elastic tissues (\%) & $88.92 \pm 4.18$ & $56.69 \pm 5.09^{\mathrm{a}}$ & $92.22 \pm 3.19$ \\
\hline \multicolumn{4}{|l|}{ Eliminatig striated muscle } \\
\hline Smooth muscle (\%) & $11.08 \pm 4.18$ & $4.66 \pm 2.77^{\mathrm{a}}$ & $7.78 \pm 3.19$ \\
\hline Elastin (\%) & $47.13 \pm 3.08$ & $35.28 \pm 4.56^{\mathrm{a}}$ & $45.27 \pm 2.56$ \\
\hline Collagen (\%) & $41.78 \pm 2.84$ & $60.06 \pm 1.89^{\mathrm{a}}$ & $46.95 \pm 4.66$ \\
\hline Thickness (mm) & $0.22 \pm 0.03$ & $0.42 \pm 0.07^{\mathrm{a}}$ & $0.38 \pm 0.02^{\mathrm{ab}}$ \\
\hline Parietal section $\left(\mathrm{mm}^{2}\right)$ & $6.68 \pm 0.91$ & $16.58 \pm 4.14^{\mathrm{a}}$ & $7.49 \pm 0.40^{\mathrm{ab}}$ \\
\hline Smooth muscle (abs) $\left(\mathrm{mm}^{2}\right)$ & $71.97 \pm 20.73$ & $41.20 \pm 13.67$ & $57.60 \pm 21.05$ \\
\hline Striated muscle (abs) $\left(\mathrm{mm}^{2}\right)$ & $0.00 \pm 0.00$ & $668.12 \pm 147.00^{\mathrm{a}}$ & $0.00 \pm 0.00^{\mathrm{b}}$ \\
\hline Total muscle (abs) $\left(\mathrm{mm}^{2}\right)$ & $71.97 \pm 20.73$ & $709.32 \pm 137.19^{\mathrm{a}}$ & $57.60 \pm 21.05^{\mathrm{ab}}$ \\
\hline Elastin (abs) $\left(\mathrm{mm}^{2}\right)$ & $316.88 \pm 64.94$ & $357.80 \pm 144.47$ & $338.38 \pm 10.07$ \\
\hline Collagen (abs) $\left(\mathrm{mm}^{2}\right)$ & $279.52 \pm 44.65$ & $591.32 \pm 147.84^{\mathrm{a}}$ & $352.70 \pm 53.52^{\mathrm{ab}}$ \\
\hline
\end{tabular}

Mean value (MV) \pm standard deviation (SD). Abs: absolute or net amount.

${ }^{\mathrm{a}} P<0.05$ with respect to jugular vein.

${ }^{\mathrm{b}} P<0.05$ with respect to vena cava.

into account the differential structural characteristics of the observed segments. The obtained results are in accordance with the well-known nonlinearity (i.e., pressure dependence) of the venous compliance in particular [14] and of the mechanical behavior of the venous wall in general. The resultant slope of the pressure-diameter relationship is less steep beneath the breakpoint (i.e., at lower pressures) than above it (i.e., at higher pressures) (Figure 1, right panel).

The data in Table 1 show that the variation in compliance values among the observed veins should not be only attributed to their geometric differences. The characteristics of the pressure-diameter relationship could be interpreted as a functional adaptation that enables the venous system to respond to the changes in load acting as a "hemodynamic damper," in order to contribute with the maintenance of the central pressures, the venous return, and the cardiac output at adequate levels $[14,15]$. If a sudden volume load occurred at pressure levels below the breakpoint, the high compliance would allow the venous wall to easily accommodate to this load, ensuring an adequate cardiac filling with no significant variation of the filling pressure. On the other hand, at pressures above the breakpoint, compliance values are lower, avoiding overdistension, venous stasis, and central pressure from falling [14]. Furthermore, it has been suggested that the presence of a low compliance region in the venous pressurediameter relationship is what enables the adoption of an erect posture in humans, with no hypotension [16].

In this context, the differences in the biomechanical response among the observed veins can be attributed to varied workloads and functional requirements that veins face, depending on the territory they are in. As an example, the transition between supine and standing positions will cause a shift of the blood from the central to the peripheral veins, for example, veins of the lower limbs. This causes a reduction of the central blood volume and the cardiac filling volume [16], which are limited and rapidly compensated in normal conditions, with small changes to the arterial pressure. The relative stiffness of the peripheral vessels may contribute 


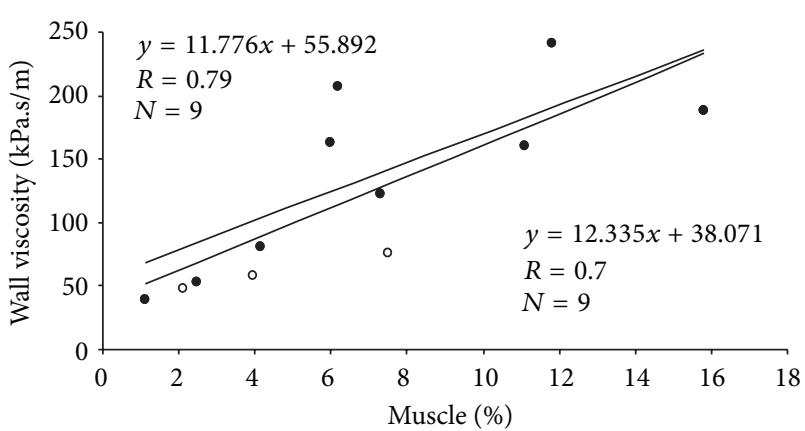

(a)

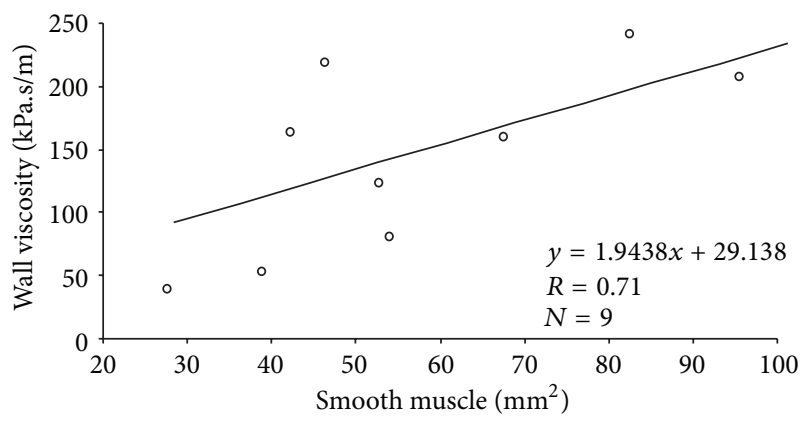

(b)

Figure 6: (a) Upper linear relationship shows the association between venous wall viscosity and the relative amounts of smooth muscle, considering the striated muscle in the total muscular vascular area (dark markers). The lower linear relationship was calculated without considering the striate muscle as part of the $100 \%$ sectional area of the vascular wall (considering only squared markers). Both linear relationships were statistically significant $(P<0.05)$. (b) Association between the viscosity of the venous wall and the absolute amount of smooth muscle, considering the striated muscle as part of the $100 \%$ of the wall section area.

to minimize the hemodynamic disturbance by limiting the displacement of fluid towards the periphery.

Even though the existence of a viscoelastic behavior in the venous wall was described almost 50 years ago [17$20]$, its relevance in the venous system physiology has been underestimated. However, venous parietal viscosity and the energy dissipation related to it may have an important functional role, allowing veins to resist strain in a frequency or velocity dependent manner and acting as dampers in hemodynamic overload conditions [21]. Furthermore, the variation of viscosity values and the energy dissipation role of the venous parietal structure may be important from a functional point of view. It is noteworthy that higher levels of viscosity and dissipated energy were observed in the peripheral vein segments. This would allow an adequate adaptative response to hemodynamic overload conditions. As an example, after postural changes or during walking, the venous workload changes rapidly. The energy dissipation in these situations would protect the venous wall and would enable the attenuation of centripetal waves.

Results showed that the relative and absolute contents of elastin, collagen, and smooth muscle varied depending on the

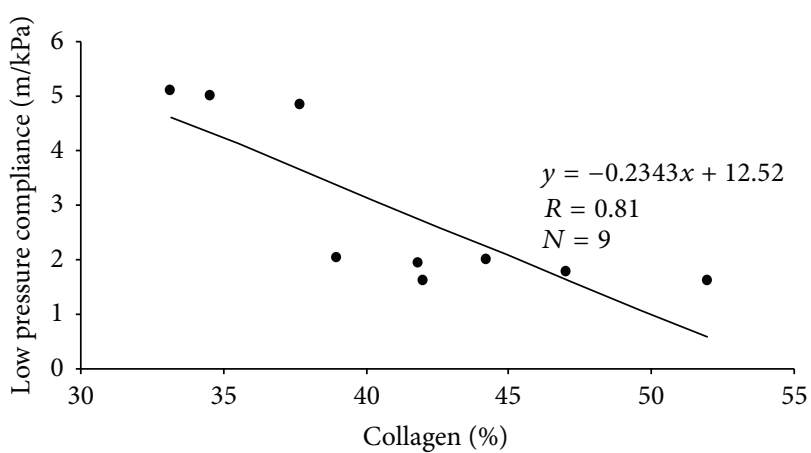

(a)

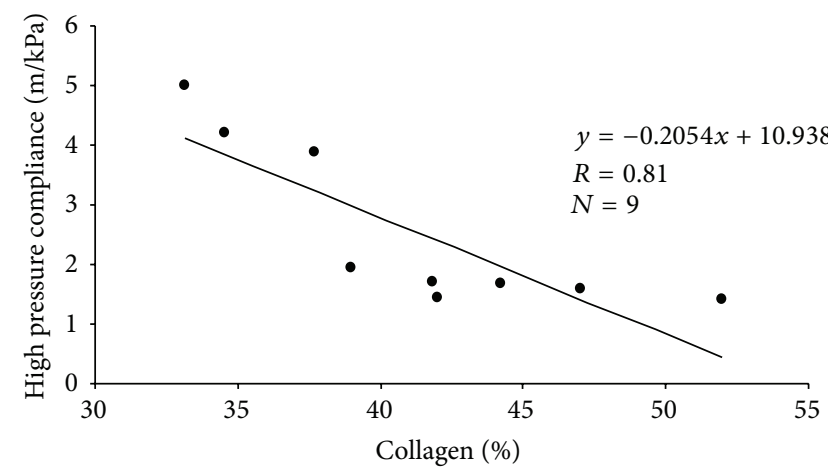

(b)

FIGURE 7: Association between venous wall viscosity and venous compliance at low pressures (a) and at high pressures (b). The linear relationship was statistically significant $(P<0.05)$.

territory from where the segments were collected. Additionally, the existence of striated muscle in the vena cava near the atrium was verified. The absolute and relative amounts of smooth muscle in the peripheral veins were higher than in central vessels (Table 3). The smooth muscle content was positively associated with the viscous properties of the venous wall (Figure 6). Consequently, the parietal viscosity and therefore the energy dissipation would be associated with the smooth muscle component. In this sense, the high energy dissipation capacity that is present in the peripheral veins, with respect to central veins, may be determined, among other factors, at least partially, by the absolute and relative component of the vascular smooth muscle. However, while comparing the jugular vein with the femoral vein, it is evident that the absolute and relative amounts of smooth muscle are not the only determinant factor of the viscous response. The femoral vein exhibited a stronger viscous response, even if the amount of smooth muscle was not significantly higher than the content in the jugular vein. This could be explained, at least partially, by the different distribution or organization of the parietal smooth muscle, or by the contribution of the other components to the viscous response. Regarding this, Silver et al. [21] have demonstrated that the collagen content in the vascular wall, rather than behaving as a purely elastic material, has a significant viscous effect.

A previous study demonstrated that ovine jugular veins exhibit the best viscous and elastic matching with human 
brachial arteries [22]. As was widely described, brachial arteries are usually used in the arteriovenous hemodialysis access confection [23]. According to the findings reported in this study, the viscoelastic differences were associated with structural variations that could be involved in the origin of the intimal hyperplasia and the vascular access dysfunction. Indeed, several works pointed out that veins collected from different territories exhibit functional changes originated at the end stage renal failure $[24,25]$; these changes are disadvantages additional to the previously existing physiological structural and functional differences described in this study.

We conclude that (1) the viscoelastic behavior of the venous wall varies depending on the vascular territory, and it is associated with the variation of the histological structure. These differences involve muscle (both smooth and striated), elastin, and collagen contents. (2) In addition, the quantity of collagen was negatively correlated with high- and lowpressure compliances, and (3) the smooth muscle content was higher in peripheral veins and is positively correlated with venous wall viscosity.

\section{Conflict of Interests}

The authors have no conflict of interests.

\section{Financial Support}

This work was supported by the René Favaloro University Foundation (Argentina), funds from "Préstamo BID OC-AR PICT08-0340" (Argentina), and Agencia Nacional de Investigación e Innovación (PRSCT-008-020; FCE-2007-635, Dr. R. Armentano and FCE-2007-638, Dr. D. Bia) (Uruguay).

\section{Acknowledgments}

This work was supported by funds of "Prestamo BID OCAR PICT08-0340." The authors gratefully acknowledge Favaloro University (Argentina), PEDECIBA, and the Comisión Sectorial de Investigación Científica (CSIC-UdelaR) of the Universidad de la República (Uruguay). In addition, the authors would like to thank Mr. Juan D. Fernandez and Ms. Paula Bia (BiaBis/Diseño Gráfico) for their contribution with the histological studies and the process of the histological images, respectively.

\section{References}

[1] R. G. Favaloro, "Bilateral internal mammary artery implants. Operative technic-a preliminary report," Cleveland Clinic Quarterly, vol. 34, no. 1, pp. 61-66, 1967.

[2] M. J. Brescia, J. E. Cimino, K. Appel, and B. J. Hurwich, "Chronic hemodialysis using venipuncture and a surgically created arteriovenous fistula," The New England Journal of Medicine, vol. 275, no. 20, pp. 1089-1092, 1966.

[3] E. I. C. Fischer, D. B. Santana, G. L. Cassanello et al., "Reduced elastic mismatch achieved by interposing vein cuff in expanded polytetrafluoroethylene femoral bypass decreases intimal hyperplasia," Artificial Organs, vol. 29, no. 2, pp. 122-130, 2005.
[4] L. Hofstra, D. C. J. J. Bergmans, A. P. G. Hoeks, P. J. E. H. M. Kitslaar, K. M. L. Leunissen, and J. H. M. Tordoir, "Mismatch in elastic properties around anastomoses of interposition grafts for hemodialysis access," Journal of the American Society of Nephrology, vol. 5, no. 5, pp. 1243-1250, 1994.

[5] D. Bia, E. I. Cabrera Fischer, Y. Zócalo et al., "Vascular accesses for haemodialysis in the upper arm cause greater reduction in the carotid-brachial stiffness than those in the forearm: study of gender differences," International Journal of Nephrology, vol. 2012, Article ID 598512, 10 pages, 2012.

[6] D. B. Santana, R. L. Armentano, Y. Zócalo et al., "Functional properties of fresh and cryopreserved carotid and femoral arteries, and of venous and synthetic grafts: comparison with arteries from normotensive and hypertensive patients," Cell and Tissue Banking, vol. 8, no. 1, pp. 43-57, 2007.

[7] T. R. Kohler and T. R. Kirkman, "Dialysis access failure: a sheep model of rapid stenosis," Journal of Vascular Surgery, vol. 30, no. 4, pp. 744-751, 1999.

[8] D. Bia, R. Armentano, D. Craiem et al., "Smooth muscle role on pulmonary arterial function during acute pulmonary hypertension in sheep," Acta Physiologica Scandinavica, vol. 181, no. 3, pp. 359-366, 2004.

[9] R. L. Armentano, J. G. Barra, J. Levenson, A. Simon, and R. H. Pichel, "Arterial wall mechanics in conscious dogs: assessment of viscous, inertial, and elastic moduli to characterize aortic wall behavior," Circulation Research, vol. 76, no. 3, pp. 468-478, 1995.

[10] R. D. Bauer, "Rheological approaches of arteries," Biorheology, vol. 21, no. 1, pp. 159-167, 1984.

[11] R. D. Bauer, R. Busse, and A. Schabert, "Separate determination of the pulsatile elastic and viscous forces developed in the arterial wall in vivo," Pflugers Archiv European Journal of Physiology, vol. 380, no. 3, pp. 221-226, 1979.

[12] F. P. Salvucci, D. Bia, R. L. Armentano et al., "Association between mechanics and structure in arteries and veins: theoretical approach to vascular graft confection," in Proceedings of the 31st Annual International Conference of the IEEE Engineering in Medicine and Biology Society: Engineering the Future of Biomedicine (EMBC'09), pp. 4258-4261, Minneapolis, Minn, USA, September 2009.

[13] M. Kawasaki, Y. Ito, H. Yokoyama et al., "Assessment of arterial medial characteristics in human carotid arteries using integrated backscatter ultrasound and its histological implications," Atherosclerosis, vol. 180, no. 1, pp. 145-154, 2005.

[14] R. Freeman, V. Lirofonis, W. B. Farquhar, and M. Risk, "Limb venous compliance in patients with idiopathic orthostatic intolerance and postural tachycardia," Journal of Applied Physiology, vol. 93, no. 2, pp. 636-644, 2002.

[15] E. Monos, V. Bérczi, and G. Nádasy, "Local control of veins: biomechanical, metabolic, and humoral aspects," Physiological Reviews, vol. 75, no. 3, pp. 611-666, 1995.

[16] H. Olsen, E. Vernersson, and T. Länne, "Cardiovascular response to acute hypovolemia in relation to age. Implications for orthostasis and hemorrhage," American Journal of Physiology, vol. 278, no. 1, pp. H222-H232, 2000.

[17] R. S. Alexander, “The peripheral venous system," in Handbook of Physiology, W. F. Hamilton and P. Dow, Eds., pp. 1075-1098, Waverly Press, Baltimore, Md, USA, 1963.

[18] M. Anliker, W. G. Yates, and E. Ogden, "Transmission of small pressure waves in the canine vena cava," The American journal of physiology, vol. 221, no. 2, pp. 644-651, 1971. 
[19] J. H. Nippa, R. H. Alexander, and R. Folse, "Pulse wave velocity in human veins," Journal of applied physiology, vol. 30, no. 4, pp. 558-563, 1971.

[20] R. L. Wesly, R. N. Vaishnav, J. C. Fuchs, D. J. Patel, and J. C. Greenfield Jr., "Static linear and nonlinear elastic properties of normal and arterialized venous tissue in dog and man," Circulation Research, vol. 37, no. 4, pp. 509-520, 1975.

[21] F. H. Silver, P. B. Snowhill, and D. J. Foran, "Mechanical behavior of vessel wall: a comparative study of aorta, vena cava, and carotid artery," Annals of Biomedical Engineering, vol. 31, no. 7, pp. 793-803, 2003.

[22] C. Galli, D. Bia, Y. Zócalo et al., "Vascular heterografts for hemodyalisis access: analysis of elastic and viscous matching factor between human and ovine vessels," Latin American Applied Research, vol. 37, no. 3, pp. 201-206, 2007.

[23] A. Hatzibaloglou, Y. Velissaris, D. Kaitzis, D. Grekas, A. Avdelidou, and D. Kiskinis, "ProCol vascular bioprosthesis for vascular access: midterm results," Journal of Vascular Access, vol. 5, no. 1, pp. 16-18, 2004.

[24] J. van der Linden, T. W. Lameris, A. H. van den Meiracker, A. A. E. A. de Smet, P. J. Blankestijn, and M. A. van den Dorpel, "Forearm venous distensibility predicts successful arteriovenous fistula," American Journal of Kidney Diseases, vol. 47, no. 6, pp. 1013-1019, 2006.

[25] M. A. Wali, R. A. Eid, M. Dewan, and M. Al-Homrany, "Preexisting histopathological changes in the cephalic vein of renal failure patients before arterio-venous fistula (AVF) construction," Annals of Thoracic and Cardiovascular Surgery, vol. 12, no. 5, pp. 341-348, 2006. 

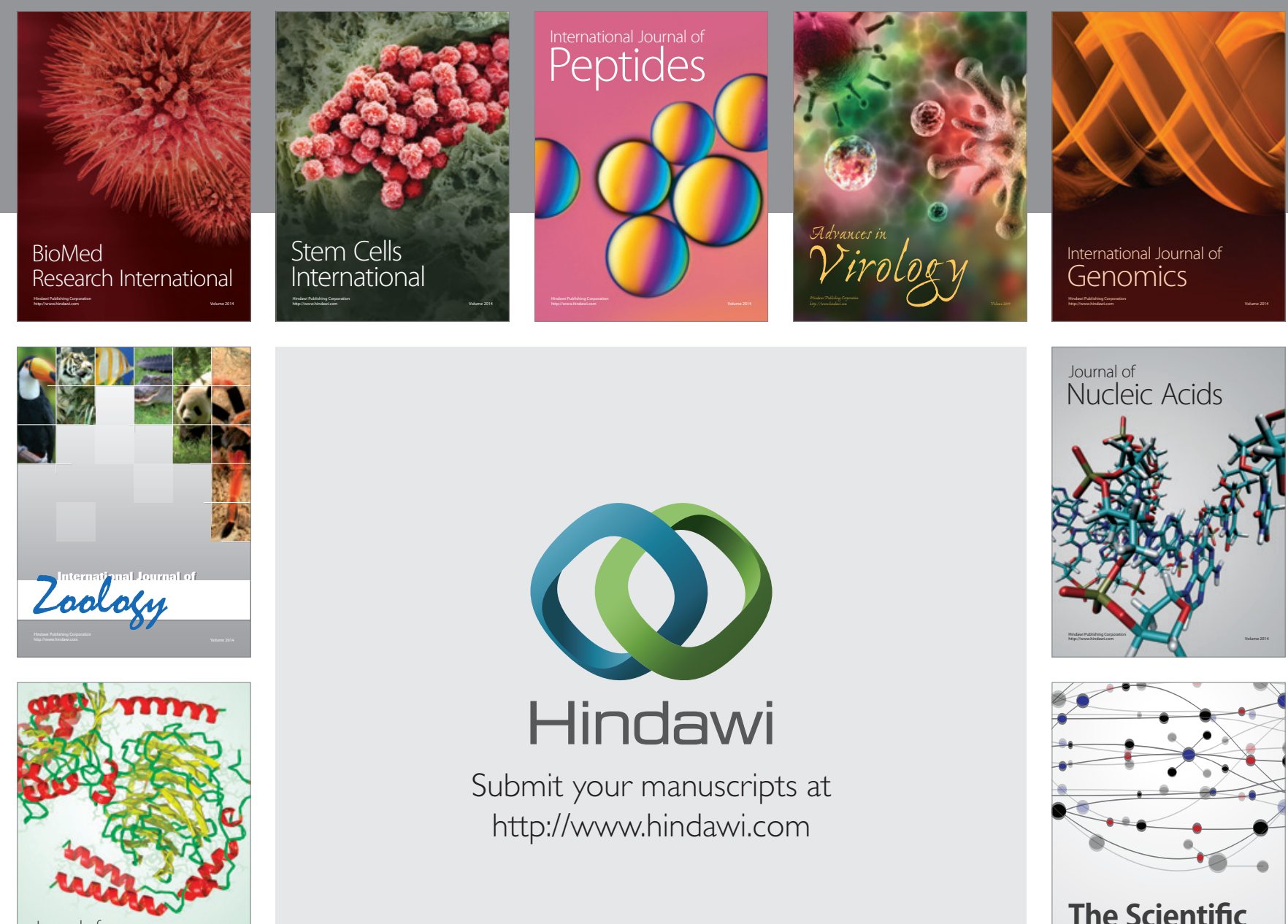

Submit your manuscripts at

http://www.hindawi.com

Journal of
Signal Transduction
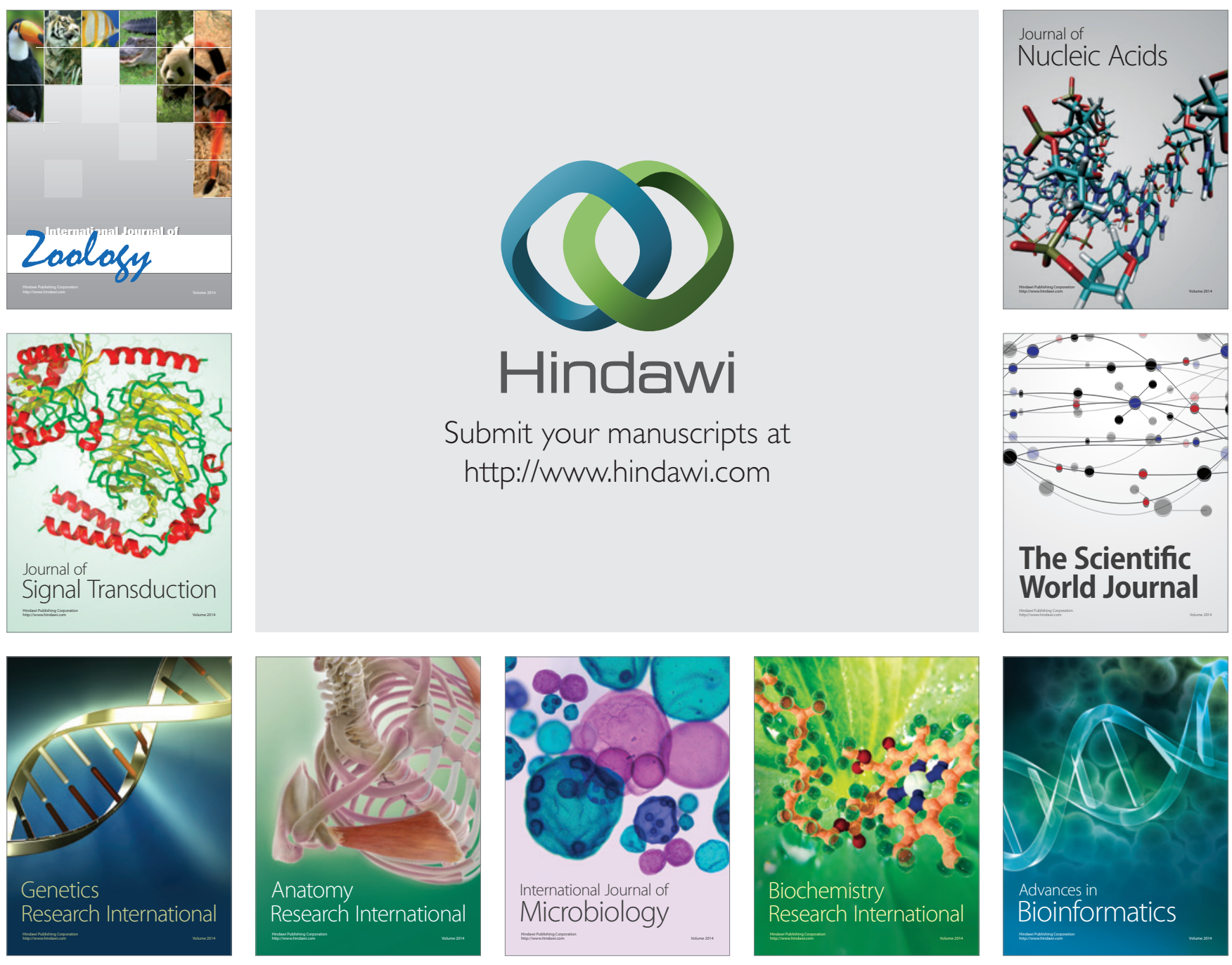

The Scientific World Journal
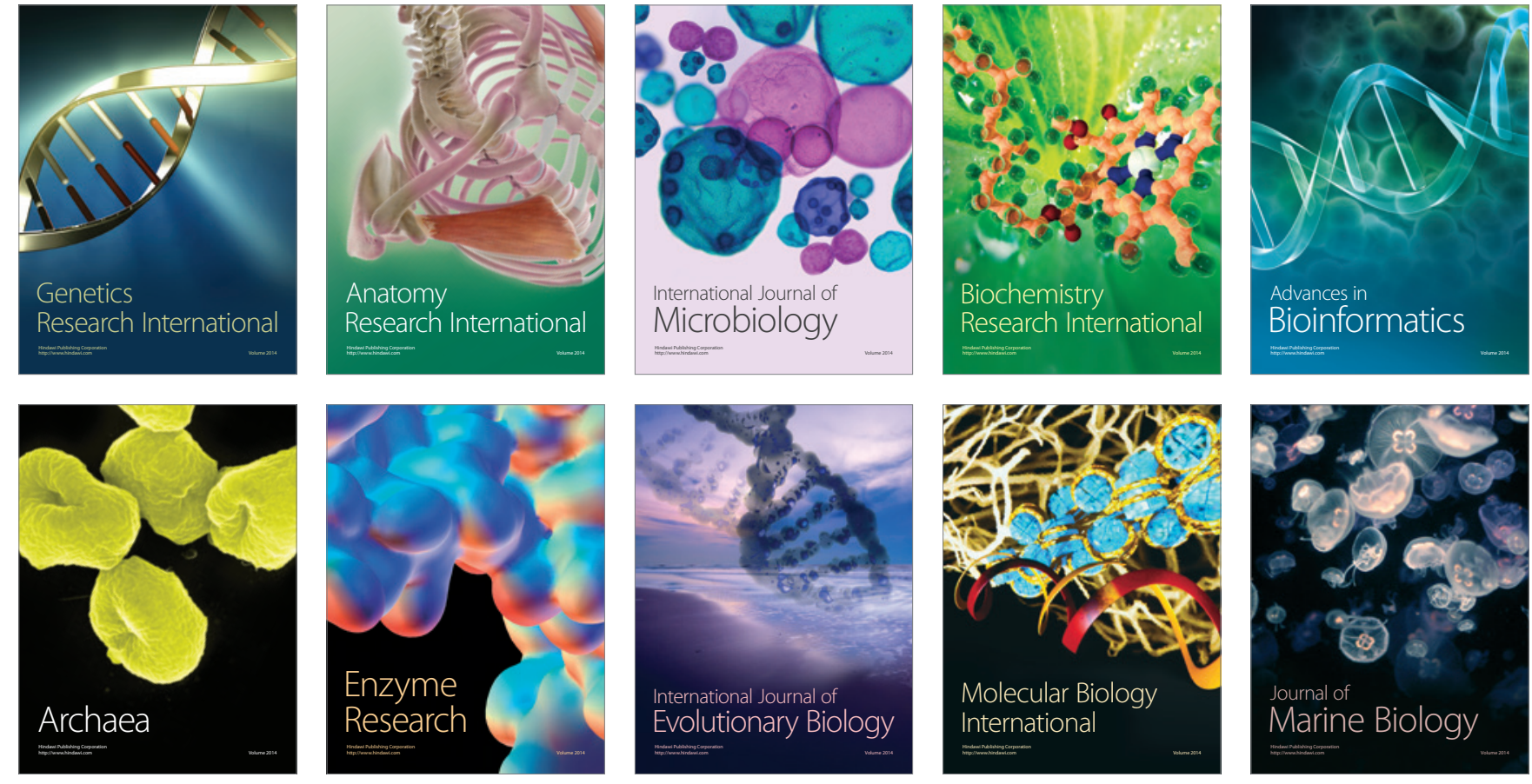